\title{
Impact of Environmental Conditions on Growth and the Phenolic Profile of Achillea atrata L.
}

\author{
Lysanne Salomon $^{1,2}$, Peter Lorenz ${ }^{1}$ (D) Bernhard Ehrmann ${ }^{3}$, Otmar Spring ${ }^{2}$, Florian C. Stintzing ${ }^{1}$ (D) \\ and Dietmar R. Kammerer $1, * \mathbb{D}$
}

1 WALA Heilmittel GmbH, Department of Analytical Development \& Research, Section Phytochemical Research, 73087 Bad Boll, Germany; lysanne.apel@gmx.de (L.S.); Peter.Lorenz@wala.de (P.L.); Florian.Stintzing@wala.de (F.C.S.)

2 Institute of Botany, Hohenheim University, 70599 Stuttgart, Germany; o.spring@uni-hohenheim.de

3 WALA Heilmittel GmbH, Department of Manufacturing, WALA Medicinal Herb Garden, 73087 Bad Boll, Germany; Bernhard.Ehrmann@wala.de

* Correspondence: dietmar.kammerer@wala.de; Tel.: +49-7164-930-6688, Fax: +49-7164-930-7080

Citation: Salomon, L.; Lorenz, P.; Ehrmann, B.; Spring, O.; Stintzing, F.C.; Kammerer, D.R. Impact of Environmental Conditions on Growth and the Phenolic Profile of Achillea atrata L. Processes 2021, 9, 853. https://doi.org/10.3390/pr9050853

Academic Editors: Luigi Menghini and Claudio Ferrante

Received: 9 April 2021

Accepted: 6 May 2021

Published: 12 May 2021

Publisher's Note: MDPI stays neutral with regard to jurisdictional claims in published maps and institutional affiliations.

Copyright: (c) 2021 by the authors. Licensee MDPI, Basel, Switzerland. This article is an open access article distributed under the terms and conditions of the Creative Commons Attribution (CC BY) license (https:// creativecommons.org/licenses/by/ $4.0 /)$

\begin{abstract}
Achillea atrata L. is a traditionally used medicinal plant. With its pronounced antimicrobial potential, this alpine Achillea species may also be used in modern phytotherapy to treat MRSA infections and prevent dermal infections, such as acne vulgaris. For the present study, A. atrata was cultivated in its natural habitat in Switzerland as well as in Germany to elucidate the potential of standardizing plant material derived from this species for pharmaceutical production. Phytochemical characterization of phenolic constituents by HPLC-DAD-MS ${ }^{n}$ revealed that environmental conditions have only a minor impact on the phenolic profile. Metabolic differences between cultivated and wild plants grown in the same environment suggested the possible existence of genetically derived chemotypes. In total, 28 substances were identified, with marked differences in the occurrence of phenolic compounds observed between flowers and leaves. Moreover, to the best of our knowledge, 7 phenolic compounds have been reported for the first time in A. atrata in the present study. The quantitation of individual constituents revealed their contents to depend on environmental factors and to reach their maximum at increasing altitudes. The results here presented may help to select and cultivate A. atrata plant material with defined and constant compound profiles, which is of particular importance for potential pharmaceutical use.
\end{abstract}

Keywords: black yarrow; chemotype; cultivation; phenolic profiling

\section{Introduction}

Achillea atrata L., commonly known as black yarrow, is native to the Alpine regions of Central, Southern, and Western Europe. This perennial herbaceous plant has a widely ramified rhizome and grows on moderately moist, stony, calcareous soils as well as scree slopes at altitudes ranging from 1300 to $4300 \mathrm{~m}$ a.s.l. The black outlined involucral bracts are characteristic and eponymous for this Achillea species, reaching a growth height of up to $25 \mathrm{~cm}$. The flower heads are arranged in a terminal raceme, with the tubular petals being pale yellow and the ligulate petals white (Figure 1). The elongated basal leaves are stalked and deeply pinnately lobed, whereas the upper leaves are sessile [1]. Aerial parts are harvested in the blossom period during July to September and used in traditional medicine as a tonic to treat bronchial troubles and laryngeal inflammations as well as pulmonary infections $[2,3]$.

In particular, the essential oil of $A$. atrata and its main components 1,8-cineol, sabinene, camphor, and $\alpha$-thujone reveal a very strong antifungal activity against micromycetes in mycelial growth assays and exhibit an even higher antifungal potential than the commercial fungicide bifonazole [2]. The presence of these oxygenated components in great amounts and/or synergistic effects between components in the essential oil of $A$. atrata result in 
enhanced antifungal activity, leading to growth inhibition of dermatophytes such as Epidermophyton floccosum and Trichophyton tonsurans [2]. In addition, four flavones and nine sesquiterpene lactones could be identified and isolated from the aerial parts of A. atrata [3]. None of the tested lactones exhibited any antimicrobial activity. On the other hand, the flavones santin, centaureidin, apigenin and its $7-O-\beta$-glucoside demonstrated in vitro inhibitory activity against Candida albicans, Bacillus subtilis, and/or Escherichia coli [3]. A. atrata contains high concentrations of the antimicrobial flavonoids apigenin, centaureidin, and nevadensin [3,4] and reveals the highest inhibitory activity against Propionibacterium acnes and Staphylococcus epidermidis when compared to Achillea millefolium L. and Achillea moschata WULFEN [4]. Moreover, A. atrata exhibits anti-MRSA (Methicillin resistant Staphylococcus aureus) potential and may be used as an alternative therapeutic agent against Staphylococcus aureus infections [4]. Our previous studies also showed that $A$. atrata, presumably due to its high phenolic content, has a pronounced antiradical activity compared to A. millefolium and might be an alternative source of natural antioxidants in pharmaceutical and medicinal applications in the future [5].
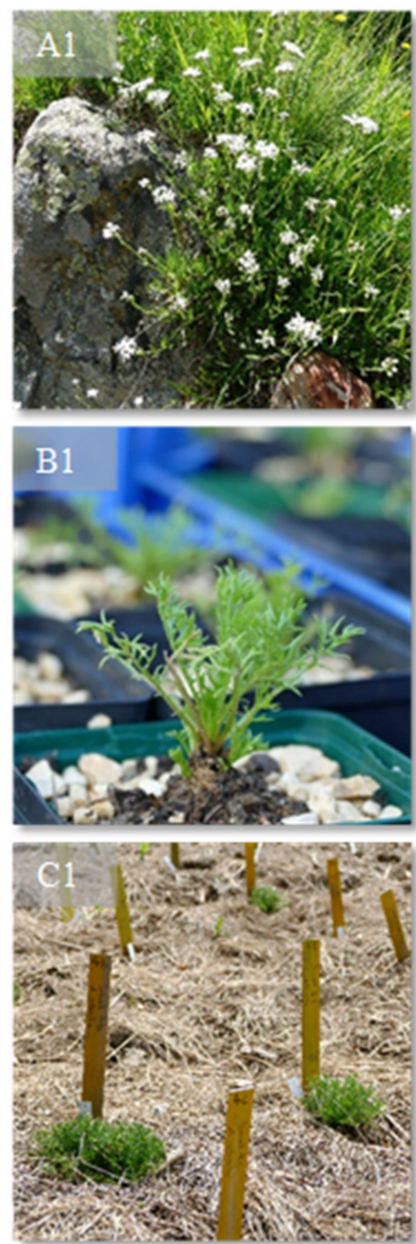
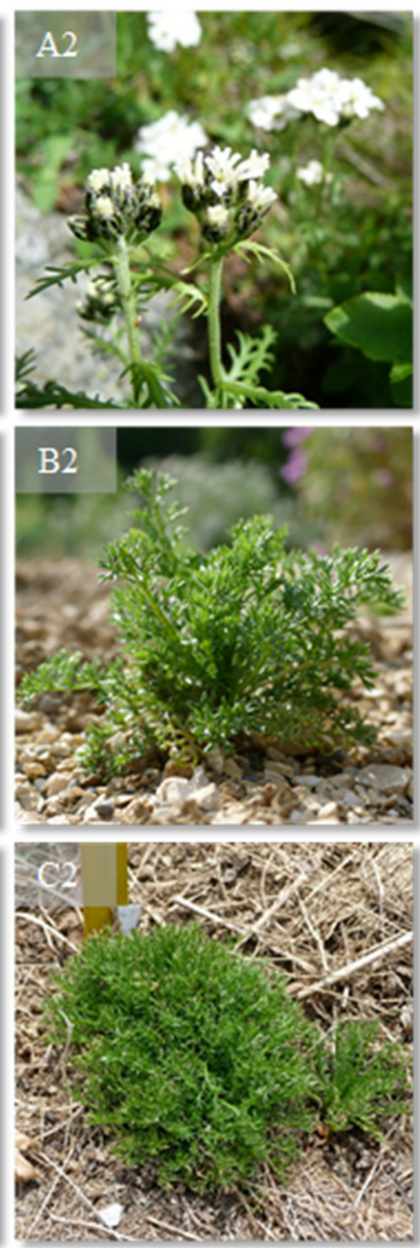
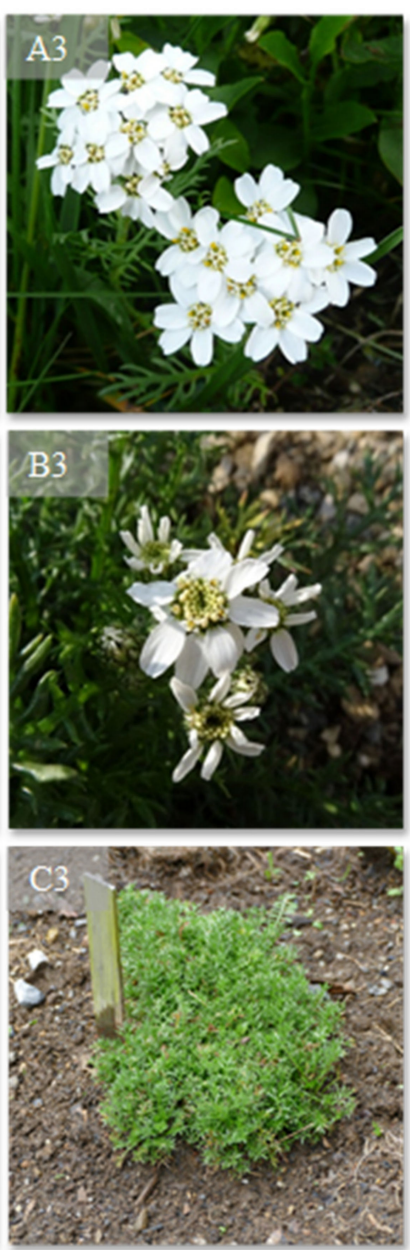

Figure 1. Achillea atrata L. from different locations. A: Natural habitat of A. atrata in the Southern Limestone Alps at an altitude of $1763 \mathrm{~m}$ a.s.l. (June 2019, A1). Side profile (A2) and close-up view (A3) of characteristic flowers with their black-edged bracts. B: A. atrata variants cultivated in Germany, under controlled conditions at $15^{\circ} \mathrm{C}$ in the greenhouse, 3 months after germination (June 2018, B1). Overview of the field experiment in Germany at an altitude of $410 \mathrm{~m}$ a.s.l. with an average plant height of up to $7 \mathrm{~cm}$ (July 2019, B2). Close-up view of the flowers of the cultivated variety with 9 flower heads $(\varnothing 0.5 \mathrm{~cm}$, September 2016, B3). C: Cultivation project in Switzerland at an altitude of $1200 \mathrm{~m}$ a.s.l. (July 2018, C1). A. atrata in the vegetative phase, with an average plant height of up to $10 \mathrm{~cm}$ and a plant width of up to $13 \mathrm{~cm}$ in the field experiment in Switzerland (July 2018, (C2) and August 2019 (C3). 
A robust cultivation leading to constant quality and quantity of bioactive compounds is a major prerequisite for the pharmacological use of this traditional medicinal plant in modern phytochemical preparations. In addition, sustainable cultivation of medicinal plants under controlled conditions offers a wide range of advantages compared to wild harvesting, such as reliable botanical identification; a lower degree of genetic, phenotypic, and phytochemical diversity as well as reduced extract variability and instability [6]. However, phytochemical studies need to clarify whether different environmental conditions (e.g., implemented through cultivation) have an impact on the secondary metabolite profile which might influence the pharmacological properties of the plants. Therefore, the aim of the present investigation was to cultivate $A$. atrata under different environmental and climatic conditions (Germany/Switzerland), to characterize and compare the specific phenolic compound profiles in different plant organs, and to quantitate selected individual phenolic compounds by HPLC-DAD-MS ${ }^{\mathrm{n}}$. Wild samples of $A$. atrata collected from its natural habitat in the Southern Limestone Alps were used to compare the secondary metabolite profile with that of samples obtained from the aforementioned cultivation experiments.

\section{Materials and Methods}

\subsection{Chemicals}

Methanol (HPLC grade) for extraction of the plant material and acetonitrile (HPLC grade) for quantification by HPLC-DAD were obtained from Th. Geyer GmbH \& Co. KG (Renningen, Germany). Acetonitrile (HPLC-MS grade) and formic acid (98\%) for HPLC-DAD-MS ${ }^{\mathrm{n}}$ analyses were purchased from Sigma-Aldrich (Steinheim, Germany). Purified water $(0.056 \mu \mathrm{S} / \mathrm{cm})$ was obtained from a Purelab Option-Q system (Elga Berkefeld $\mathrm{GmbH}$, Celle, Germany). The following reference standards were used: luteolin and 5caffeoylquinic acid (chlorogenic acid) from PhytoLab GmbH \& Co. KG (Vestenbergsgreuth, Germany); quercetin-3-O-rutinoside, apigenin, and apigenin-7-O-glucoside from Carl Roth GmbH \& Co. KG (Karlsruhe, Germany).

\subsection{Achillea atrata L. Plant Material from Its Natural Habitat}

Leaves and flowers of A. atrata were harvested in August 2019 in the Southern Limestone Alps of Switzerland (Canton Valais) at an altitude of $1763 \mathrm{~m}$ a.s.l. Prior to analysis, the flowers and leaves were manually separated and kept at $-80^{\circ} \mathrm{C}$ until extraction. The plant material was identified by Dr. phil. Rhinaixa Duque-Thüs (Institute of Botany, Hohenheim University, Stuttgart, Germany), and a voucher was deposited in the herbarium of the Institute of Botany at Hohenheim University (HOH-022701).

\subsection{Cultivation of Achillea atrata $L$.}

Seeds of A. atrata obtained from the botanical garden of the University of Zurich (CH-O-Z 2015 1068/1069) were germinated and plants were cultivated in Germany (WALA Heilmittel GmbH, medicinal herb garden, Bad Boll) as well as in Switzerland (Schweibenalp, Brienz) at altitudes of 410 and 1200 m a.s.l., respectively, in the years 2015 to 2019 (Germany) and 2016 to 2019 (Switzerland), respectively. For cultivation in Germany, germination of the seeds was carried out under controlled conditions in a greenhouse at a temperature of $15^{\circ} \mathrm{C}$. The soil consisted of $32 \%$ wood fiber (GreenFibre ${ }^{\circledR}$ untreated; Klasmann-Deilmann $\mathrm{GmbH}$, Geeste, Germany), 64\% compost, and 4\% sand. An optimized soil composition (s. 3.1) of $20 \%$ sand, $25 \%$ volcanic granulate, $25 \%$ wood fiber compost, and $30 \%$ limestone gravel (variant 1) was used for cultivation in the field. New seeding was carried out every year due to pest infestation and weak hibernation in the field. Cultivation experiments in Switzerland were performed with peat-free soil consisting of bark humus and mineral structural materials (Bio Kräutererde ohne Torf; Ökohum GmbH, Herbertingen, Germany), and sand. This soil was applied for the first cultivation step in the greenhouse under controlled conditions. For planting in the field, the following soil composition was used: 70\% compost, $15 \%$ wood fiber, $5 \%$ clay, $5 \%$ lava granules and limestone (Öko Gärtnerei Maurer, Münsingen, Switzerland). The plants, consisting of full blooming flowers and leaves, were 
harvested at both locations in August 2019. The different plant organs were separated manually and stored at $-80{ }^{\circ} \mathrm{C}$ until phytochemical analysis. Details of the cultivation experiments performed at the two locations in Germany and Switzerland are presented in Supplementary Tables S1 and S2. Specimens of $A$. atrata from both locations were deposited at the herbarium of Hohenheim University (HOH-022702 and $\mathrm{HOH}-022703)$.

\subsection{Extraction of the Plant Material}

Aliquots of $3.2 \mathrm{~g}$ of frozen leaves or flowers from different A. atrata plants of the different samples were cut into small pieces and comminuted with mortar and pestle for $15 \mathrm{~min}$. This plant material was mixed with $30 \mathrm{~mL}$ methanol and extracted for $24 \mathrm{~h}$ at $5{ }^{\circ} \mathrm{C}$ in the dark. As only one inflorescence with about 9 flower heads could be harvested from the German cultivation site for phytochemical analysis, $1.5 \mathrm{~g}$ of flower material was used and extracted with $15 \mathrm{~mL}$ methanol. Subsequently, the suspension was filtered over Celite ${ }^{\circledR}$ through a Buechner funnel by vacuum suction. The solid residue was re-extracted with methanol for another $24 \mathrm{~h}$, and the respective supernatants were combined. The solvent was removed by rotary evaporation to yield $4.5 \mathrm{mg}$ residue from flowers and $18 \mathrm{mg}$ from leaves of the German cultivation site, $16 \mathrm{mg}$ from leaves of the Swiss cultivation site, $9 \mathrm{mg}$ from flowers, and $14 \mathrm{mg}$ from leaves from the wildly growing plant material. For phytochemical analyses by HPLC-DAD-MS ${ }^{n}$ and quantitation of individual phenolic compounds by HPLC-DAD, the plant extracts were dissolved in methanol/water $(1: 1 ; v / v)$ at a concentration of $0.5 \mathrm{mg} / \mathrm{mL}$ and analyzed in triplicate.

\subsection{HPLC-DAD-MS Analyses}

Chromatographic analyses were performed with an Agilent 1200 HPLC system (Agilent, Waldbronn, Germany) equipped with a vacuum degasser (G1379B), a binary pump (G1312A), an autosampler (G1329A), a thermostatted column compartment (G1316A), and a diode array detector (G1315B). A SunFire C18 reversed-phase column (100 A, $3.5 \mu \mathrm{m}, 150 \mathrm{~mm} \times 2.1 \mathrm{~mm}$, Waters, Wexford, Ireland) was used at $25^{\circ} \mathrm{C}$ and a flow rate of $0.21 \mathrm{~mL} / \mathrm{min}$ using an injection volume of $20 \mu \mathrm{L}$. A gradient binary eluent system (eluent A: $0.1 \%$ formic acid $(v / v)$; eluent B: acetonitrile) was applied with the following gradient system: 0-6 $\mathrm{min}, 0 \% \mathrm{~B} ; 6-9 \mathrm{~min}, 0 \%-5 \% \mathrm{~B} ; 9-14 \mathrm{~min}, 5 \%-10 \% \mathrm{~B} ; 14-19 \mathrm{~min}$, 10\%-15\% B; 19-37 min, 15\%-20\% B; 37-48 $\mathrm{min}, 20 \%-35 \% \mathrm{~B} ; 48-62 \mathrm{~min}, 35 \%-100 \% \mathrm{~B}$; 62-68 $\mathrm{min}, 100 \% \mathrm{~B} ; 68-78 \mathrm{~min}, 100 \%-0 \% \mathrm{~B} ; 78-84 \mathrm{~min}, 0 \% \mathrm{~B}$. The detection of phenolic compounds was carried out at 210, 220, 254, 280, and $366 \mathrm{~nm}$. The LC system was coupled to an HCT ultra ion trap MS detector interfaced with an ESI ion source (Bruker Daltonik $\mathrm{GmbH}$, Bremen, Germany) operating in the negative ionization mode and applying the following device parameters: dry gas flow rate $\left(\mathrm{N}_{2}\right), 8 \mathrm{~L} / \mathrm{min}$; nebulizer pressure, 40 psi; capillary temperature, $359^{\circ} \mathrm{C}$. MS spectra were recorded in a range of $m / z 50$ to 1500 with a compound stability and trap drive level of $100 \%$. For data acquisition, the software Agilent Chemstation (Rev. B.01.03 SR1) (Agilent, Waldbronn, Germany) and Bruker Daltonik esquire control (Version 6.1) (Bruker Daltonik GmbH, Bremen, Germany) were used [7].

\subsection{HPLC-DAD Analyses}

HPLC-DAD analyses of the plant organ extracts were performed on a Thermo Fisher Scientific Dionex Ultimate 3000 RSLC system (Thermo Fisher Scientific GmbH, Dreieich, Germany), equipped with a binary pump HPG-3400 A, an autosampler WPS-3000 TSL, a thermostatted column compartment TCC-3000 SD and a diode array detector DAD-3000. The aforementioned stationary phase and eluent system were also used for quantitation applying an injection volume of $20 \mu \mathrm{L}$ of each extract. All analyses were run in triplicate. Detection of phenolic compounds was performed at $280 \mathrm{~nm}$ and $366 \mathrm{~nm}$. Data acquisition and processing was performed with Chromeleon V 7. 2. 10 software (Dionex, Idstein, Germany). Chlorogenic acid and its isomers were quantitated at $280 \mathrm{~nm}$, whereas the flavonoid glycosides and aglycones were quantitated at $366 \mathrm{~nm}$. Five point calibration curves were obtained by injection of solutions of known concentrations $(1 \mu \mathrm{g} / \mathrm{mL}-450 \mu \mathrm{g} / \mathrm{mL})$ of the 
following standard compounds: apigenin $\left(y=3.9101 x+7.0501 ; R^{2}=0.9996\right)$, apigenin7 -O-glucoside $\left(\mathrm{y}=2.9415 \mathrm{x}-1.5111 ; \mathrm{R}^{2}=0.9997\right)$, chlorogenic acid $(\mathrm{y}=2.11 \mathrm{x}+16.944$; $\left.R^{2}=0.9989\right)$, luteolin $\left(y=5.2435 x+6.4075 ; R^{2}=0.9996\right)$, and quercetin-3-O-rutinoside $\left(y=2.5161 x+0.2018 ; R^{2}=0.9999\right)$.

\section{Results}

\subsection{Cultivation of A. atrata $L$.}

Our cultivation experiments performed in Germany and Switzerland were based on the results of previous studies by Schuetz (1988) [8]. For this purpose, germination was carried out in a greenhouse under controlled conditions, whereas the establishment and development of the plants was field researched. The development of A. atrata in Germany at an altitude of $410 \mathrm{~m}$ a.s.l. was continuous. For this reason, vegetative propagation by means of lateral shoots would have been possible only in individual cases and, thus, was not applied in our cultivation experiments. Three to four months after seeding, the plants reached a height of $\sim 4 \mathrm{~cm}$ and were transplanted to the field. Preliminary tests revealed an optimal soil composition of $20 \%$ sand, $25 \%$ volcanic granulate, $25 \%$ wood fiber compost, and 30\% limestone gravel for this alpine Achillea species. In 2019, 25 of previously 37 plants were transplanted applying the aforementioned substrate. However, only eight of them survived and one plant blossomed. Two A. atrata plants were in flower in 2016 and 2019. The first flowering Achillea was used for renewed seed production. The second one was harvested and applied for subsequent phytochemical analyses. Cultivation of A. atrata was also performed in the Limestone Alps of Switzerland at an altitude of $>1200 \mathrm{~m}$ a.s.l., which reflects its natural habitat in terms of altitude and climatic conditions. The development of A. atrata was slow, and thus plants were only transplanted to the field after 6 months of cultivation under controlled conditions. Compost-rich soil with $70 \%$ compost, $15 \%$ wood fiber, $5 \%$ clay, $5 \%$ lava granules and limestone was found favorable for the development of A. atrata. The plants reached a bushy, vigorous phenotype and developed numerous lateral shoots, which allowed vegetative propagation. However, none of the cultivated plants reached the generative phase.

The phenotype of the wild type and cultivated A. atrata variants only revealed minor differences (Figure 1, A1-C3). Thus, plants cultivated in Switzerland were more extensive in their growth, formed lateral shoots, and reached a height of up to $10 \mathrm{~cm}$ (Figure 1, C2,C3). In comparison, plants cultivated in Germany achieved an average height of $7 \mathrm{~cm}$ (Figure 1, B2) and only formed lateral shoots sporadically. Instead, the latter formed inflorescences with up to nine flower heads (Figure 1, B3). In contrast, wild plants collected in the Limestone Alps of Switzerland at an altitude of $1763 \mathrm{~m}$ a.s.l. reached a growth height of up to $20 \mathrm{~cm}$ and produced large numbers of inflorescences (Figure 1, A1-A3). In addition, the leaves were less fleshy upon cultivation under alpine conditions. All other phenotypic characteristics of cultivated A. atrata plants were identical to the wild type.

\subsection{Comparison of the Secondary Metabolite Profiles of A. atrata L. Plants Grown under Different Environmental Conditions}

The metabolite profiles of phenolic compounds from ray flowers (Figure 2) and leaves (Figure 3) of A. atrata were compared by HPLC-DAD-MS analysis of their methanolic extracts. Overall, a total of 28 compounds were identified based on their specific mass spectrometric data, UV characteristics, retention times compared with databases and literature data (Table 1). Among them dimethyl-O-ellagic acid (1), a syringic acid-Ohexoside (2), a protocatechuic acid-O-hexoside (3), chlorogenic acid (4), a $p$-coumaroyl acid derivative (5), an apigenin-6,8-di-C-hexoside (6), schaftoside (7), quercetin- $O$-hexoside (8), a dimethoxyflavanone derivative (9), 4-methyl-3-methoxy-9a-hydroxyligballinol-Oglucoside (formate adduct, 10), quercetin-3-O-rutinoside (11), a dicaffeoylquinic acid- $O$ hexoside (12), a mearnsetin-O-hexoside (13), luteolin-O-hexoside (14), an isorhamnetin-Ohexoside (15), kaempferol-3-O-rutinoside (16), a dimethoxy-myricetin-hexoside (17), apigenin-7-O-glucoside (18), dicaffeoylquinic acids $(19,20,21,22,23)$, caffeoyl-feruloylquinic 
acid (24), luteolin (25), apigenin (26), centaureidin (27), and nevadensin (28) were assigned based on their HPLC-DAD-MS ${ }^{n}$ data. The majority of identified compounds was present both in ray flowers and leaves (Table 1). Still, a number of compounds could not be unambiguously assigned. A direct comparison of the metabolite profiles of cultivated A. atrata variants and the wild type revealed that environmental conditions had a minor impact on the compound profiles, whereas the genotype appears to be more important. Only the following differences were observed in a direct comparison of the two cultivated A. atrata variants and the wild type: a dimethyl-O-ellagic acid isomer (1), a syringic acid-O-hexoside (2), and a caffeoyl-feruloylquinic acid (24) were only detected in the flowers of $A$. atrata plants cultivated in Germany. In contrast, wild type flowers were completely devoid of these compounds. When comparing leaf constituents of the variant from Germany and the wild type, seven differing compounds were detected, with quercetin$O$-hexoside (8) and luteolin-O-hexoside (14) being only found in leaf material of plants cultivated in Germany. In contrast, a $p$-coumaroyl acid derivative (5), a mearnsetin-Ohexoside (13), an isorhamnetin-O-hexoside (15), a dimethoxy-myricetin-hexoside (17), and nevadensin (28) were confirmed as leaf components only for the wild type. Furthermore, five differing compounds were observed upon comparison of the leaf metabolite profile of both cultivated variants, with the syringic acid-O-hexoside (2), the protocatechuic acidO-hexoside (3), and quercetin-3-O-hexoside (8) being exclusively identified in the leaves of plants cultivated in Germany. When comparing the leaf extracts, most prominent differences were observed between plants cultivated in Switzerland and wild type plants. The syringic acid-O-hexoside (2), the protocatechuic acid-O-hexoside (3), the $p$-coumaroyl acid derivative (5), the mearnsetin-O-hexoside (13), the isorhamnetin-O-hexoside (15), the dimethoxy-myricetin-hexoside (17), and nevadensin (28) occurred in the wild type leaves only and were not detected in the Swiss cultivated variant. In addition, our quantitative studies revealed that the highest concentration of chlorogenic acid of $49 \pm 0.1 \mathrm{~g} / \mathrm{kg}$ FW (fresh weight) was determined in the wild type leaves from the sites at highest altitude (Table 2). In contrast to chlorogenic acid, the highest amounts of dicaffeoylquinic acids were detected in the flowers of wild type plants. In particular, the dicaffeoylquinic acid (20), which occurred in both plant organs of all investigated $A$. atrata plants, revealed a maximal amount of $235 \pm 0.7 \mathrm{~g} / \mathrm{kg}$ FW in the wild type flowers. 
Intensity

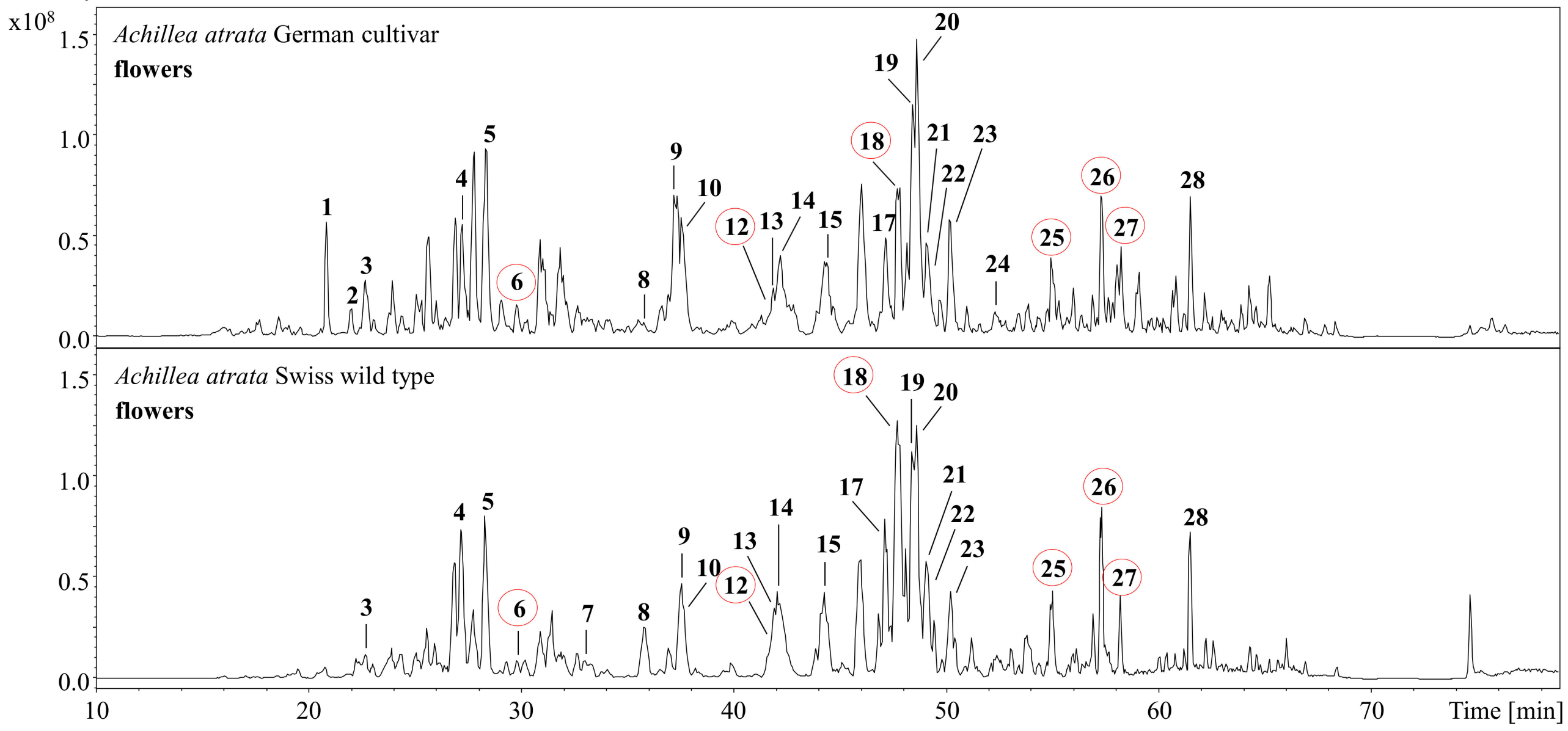

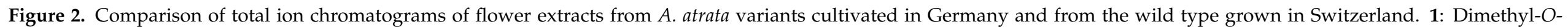

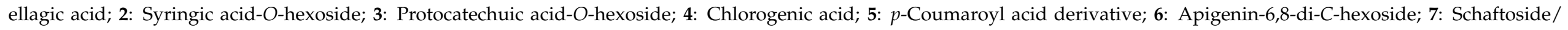

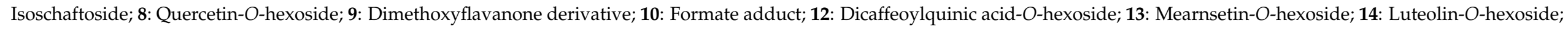

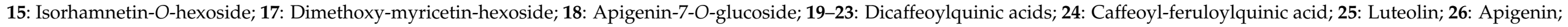
27: Centaureidin; 28: Nevadensin. Compounds exclusively detected in the flowers but not in the leaves are highlighted in red. 


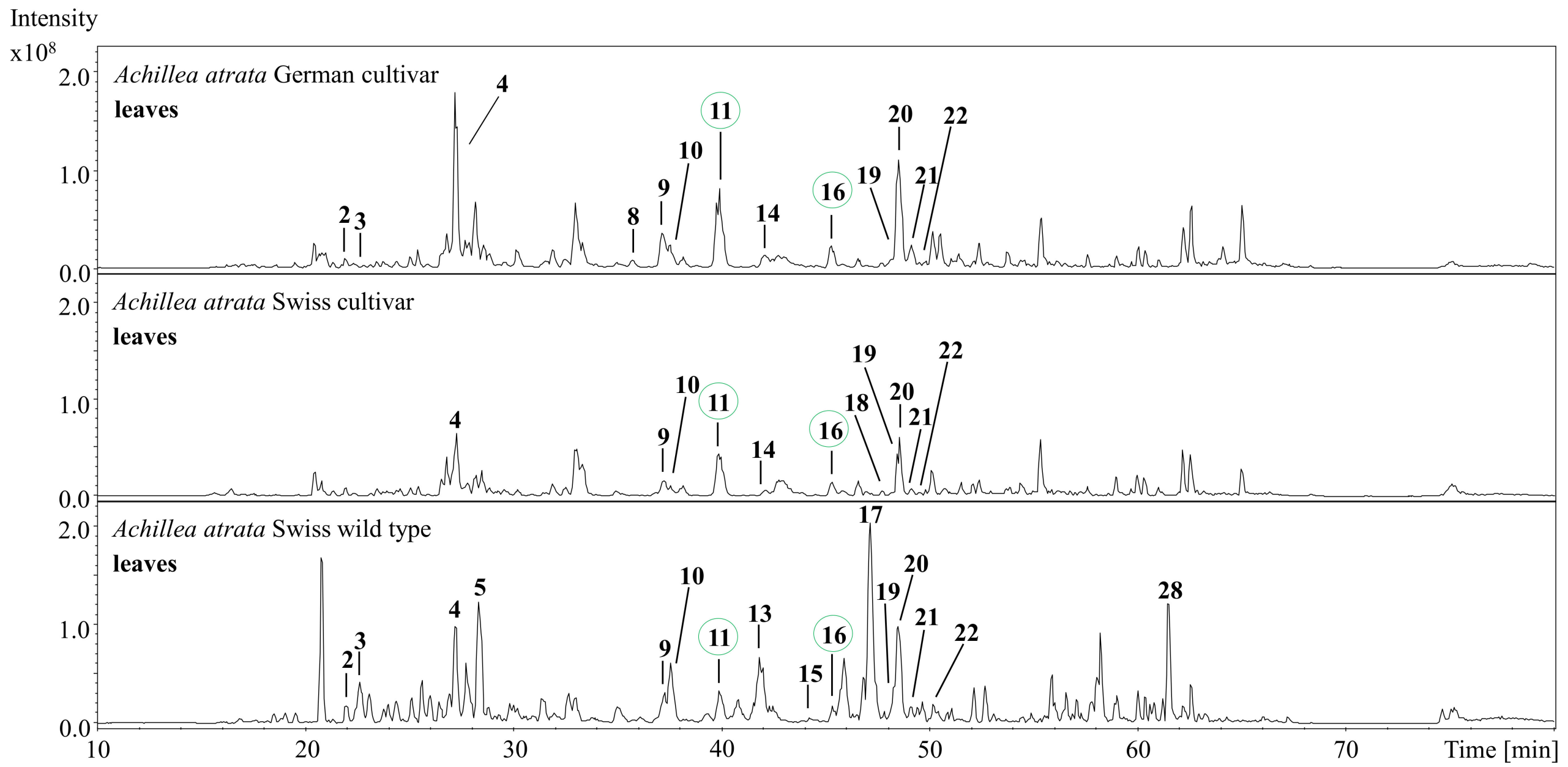

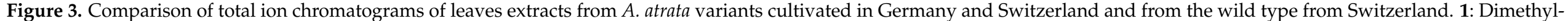

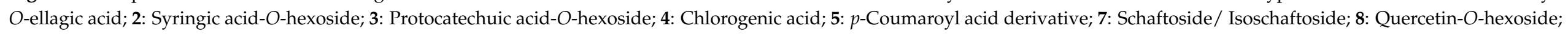

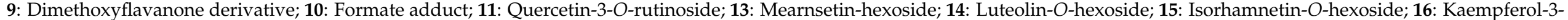

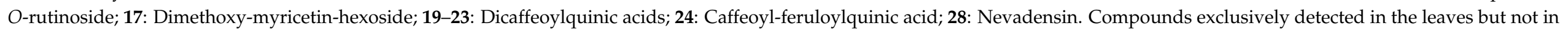
flowers are highlighted in green. 


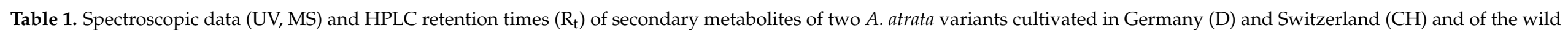
type $(\mathrm{CH})$. For fragmentation experiments only the most intensive $m / z$ ratios are given.

\begin{tabular}{|c|c|c|c|c|c|c|c|c|c|c|c|c|}
\hline \multirow[t]{2}{*}{$\begin{array}{c}\text { Peak } \\
\text { no. }\end{array}$} & \multirow[t]{2}{*}{$\begin{array}{c}\mathbf{R t} \\
{[\mathrm{min}]}\end{array}$} & \multirow[t]{2}{*}{$\begin{array}{c}\text { Peak } \\
\text { Assignment }\end{array}$} & \multirow[t]{2}{*}{$\begin{array}{c}\mathrm{UV} \lambda_{\max } \\
{[\mathrm{nm}]}\end{array}$} & \multicolumn{3}{|c|}{ MS $^{\text {n }}$ Data $[m / z]$} & \multicolumn{2}{|c|}{$\begin{array}{l}\text { A. atrata D } \\
\text { Cultivar }\end{array}$} & \multirow{2}{*}{$\begin{array}{c}\begin{array}{c}\text { A. atrata } \mathrm{CH} \\
\text { Cultivar }\end{array} \\
\text { Leaves }\end{array}$} & \multicolumn{2}{|c|}{$\begin{array}{l}\text { A. atrata } \mathrm{CH} \\
\text { Wild Type }\end{array}$} & \multirow[t]{2}{*}{ Reference } \\
\hline & & & & $\mathrm{MS}^{1}$ & $\mathrm{MS}^{2}$ & $\mathrm{MS}^{3}$ & Flowers & Leaves & & Flowers & Leaves & \\
\hline 1 & 20.9 & Dimethyl-O-ellagic acid & - & 329 & 314 & 299 & + & - & - & - & - & [9] \\
\hline 2 & 22.0 & Syringic acid-O-hexoside & 206 & 359 & 197 & 182 & + & + & - & - & + & [9] \\
\hline 3 & 22.7 & Protocatechuic acid-O-hexoside & 206,318 & 315 & 153 & 109 & + & + & - & + & + & [9] \\
\hline 4 & 27.3 & Chlorogenic acid & 218,326 & 353 & 191 & 173 & + & + & + & + & + & RS \\
\hline 5 & 28.3 & $p$-Coumaroyl acid derivative & 326 & 387 & 207 & 163 & + & - & - & + & + & [10] \\
\hline 6 & 29.4 & Apigenin-6,8-di-C-hexoside & 206,328 & 593 & 473 & 353 & + & - & - & + & - & [9] \\
\hline 7 & 33.0 & Schaftoside/Isoschaftoside & 204,336 & 563 & 353 & 325 & - & - & - & + & - & [11] \\
\hline 8 & 35.8 & Quercetin-O-hexoside & 358 & 463 & 301 & 283 & + & + & - & + & - & [10] \\
\hline 9 & 37.3 & Dimethoxyflavanone derivative & 242 & 567 & 341 & 314 & + & + & + & + & + & [9] \\
\hline 10 & 37.6 & Formate adduct ${ }^{* 1}$ & 202,278 & 565 & 339 & 324 & + & + & + & + & + & [9] \\
\hline 11 & 40.0 & Quercetin-3-O-rutinoside & 258,354 & 609 & 301 & 179 & - & + & + & - & + & RS \\
\hline 12 & 41.7 & Dicaffeoylquinic acid-O-hexoside & 204,326 & 677 & 515 & 353 & + & - & - & + & - & [9] \\
\hline 13 & 41.8 & Mearnsetin-O-hexoside & 268,348 & 493 & 331 & 316 & + & - & - & + & + & [12] \\
\hline 14 & 42.1 & Luteolin-O-hexoside & 266,348 & 447 & 285 & 255 & + & + & + & + & - & [13] \\
\hline 16 & 45.3 & Kaempferol-3-O-rutinoside & 266,342 & 593 & 285 & 255 & - & + & + & - & + & [9] \\
\hline 17 & 47.2 & Dimethoxy-myricetin-hexoside & 202,326 & 507 & 345 & 330 & + & - & - & + & + & [14] \\
\hline 18 & 47.8 & Apigenin-7-O-glucoside & 268,338 & 431 & 269 & 225 & + & - & - & + & - & RS \\
\hline 19 & 48.2 & Dicaffeoylquinic acid & 218,328 & 515 & 353 & 191 & + & + & + & + & + & [9] \\
\hline 20 & 48.4 & Dicaffeoylquinic acid & 218,328 & 515 & 353 & 191 & + & + & + & + & + & [9] \\
\hline 21 & 49.0 & Dicaffeoylquinic acid & 222,328 & 515 & 353 & 191 & + & + & + & + & + & [9] \\
\hline 22 & 49.3 & Dicaffeoylquinic acid & 222,328 & 515 & 353 & 191 & + & + & + & + & + & [9] \\
\hline 23 & 50.3 & Dicaffeoylquinic acid & 222,328 & 515 & 353 & 191 & + & - & - & + & - & [9] \\
\hline 24 & 52.5 & Caffeoyl-feruloylquinic acid & 200,336 & 529 & 367 & 191 & + & - & - & - & - & [15] \\
\hline 25 & 55.1 & Luteolin & 254,348 & 285 & 241 & 217 & + & - & - & + & - & RS \\
\hline 26 & 57.4 & Apigenin & 268,336 & 269 & 225 & - & + & - & - & + & - & RS \\
\hline 27 & 58.2 & Centaureidin & 358 & 359 & 344 & 329 & + & - & - & + & - & [16] \\
\hline 28 & 61.9 & Nevadensin & 344 & 343 & 328 & 313 & + & - & - & + & + & [17] \\
\hline
\end{tabular}


Table 2. Quantitation of selected phenolic compounds in two cultivated A. atrata variants (Germany/D, Switzerland/CH) and in the wild type (Switzerland/CH).

\begin{tabular}{|c|c|c|c|c|c|c|}
\hline \multirow[t]{2}{*}{ Peak no. } & \multirow[t]{2}{*}{ Compound } & \multicolumn{2}{|c|}{$\begin{array}{l}\text { A. atrata D } \\
\text { Cultivar } * 1\end{array}$} & \multirow{2}{*}{$\begin{array}{c}\text { A. atrata } \mathrm{CH} \\
\text { Cultivar } \\
* 1\end{array}$} & \multicolumn{2}{|c|}{$\begin{array}{l}\text { A. atrata } \mathrm{CH} \\
\text { Wild Type }^{* 1}\end{array}$} \\
\hline & & Flowers & Leaves & & Flowers & Leaves \\
\hline 4 & Chlorogenic acid & $28.5(0.11)$ & $35.1(0.08)$ & $2.6(0.06)$ & $24.4(0.11)$ & $49.0(0.09)$ \\
\hline 11 & $\begin{array}{l}\text { Quercetin-3-O- } \\
\text { rutinoside }\end{array}$ & - & $9.0(0.01)$ & $3.5(0.03)$ & - & $3.4(0.08)$ \\
\hline 18 & Apigenin-7-O-glucoside & $28.2(0.17)$ & - & - & $221.2(0.17)$ & - \\
\hline 20 & Dicaffeoylquinic acid $* 2$ & $87.3(0.71)$ & $11.2(0.37)$ & $6.0(0.06)$ & $235.5(0.73)$ & $36.8(0.05)$ \\
\hline 25 & Luteolin & $2.8(0.03)$ & - & - & $5.4(0.1)$ & - \\
\hline 26 & Apigenin & $6.0(0.11)$ & - & - & $40.5(0.07)$ & - \\
\hline
\end{tabular}

*1 g/kg FW (fresh weight) (+/- standard deviation); ${ }^{2}$ Chlorogenic acid equivalent: Calculation was performed using the chlorogenic acid calibration curve; $\mathrm{n}=5$.

\subsection{Identification of Novel Secondary Metabolites in A. atrata L.}

The phenolic acid dimethyl-O-ellagic acid (1) at a retention time of 20.9 min has neither been published for other Achillea species nor generally for the Asteraceae family before. Compound 1 exhibited an $[\mathrm{M}-\mathrm{H}]^{-}$ion at $m / z 329$ as well as the presence of two aromatic methoxyl groups, as could be deduced from the fragment ions at $m / z 314$ and $m / z 299$ indicating the loss of two methyl radicals upon collision-induced dissociation (CID). Based on the findings provided by Khallouki et al. (2006) [18], the presence of the 3,3'-O-dimethyl-ellagic acid or 3,4'-O-dimethyl-ellagic acid isomer (Figure 4) may be assumed. However, unambiguous structure elucidation is still needed for corroborating the exact isomer. In addition, two further compounds $(2,3)$ not described for this alpine Achillea species so far were identified. Compound 2 (Figure 5) at a retention time of $22.0 \mathrm{~min}$ exhibited an $[\mathrm{M}-\mathrm{H}]^{-}$ion at $m / z 359$ and the loss of one hexose moiety yielding a fragment ion at $m / z$ 197. Consequently, a syringic acid-O-hexoside was assigned to this compound, which was corroborated by comparison of its HPLC-DAD-MS ${ }^{\text {n }}$ characteristics with those reported by Spínola and Castilho (2017) [9]. The second novel compound, a protocatechuic acid-O-hexoside (3), was characterized by its mass spectrometric behavior revealing an [M-H] $]^{-}$ion at $m / z 315$ and fragment ions at $m / z 153$ and $m / z 109$ indicating the successive release of a hexose (162 Da) and a $\mathrm{CO}_{2}$ moiety (44 Da) [19]. It has also previously been reported for the medicinal plants Paeonia rubra and Curcuma zedoaria, which are used in traditional Chinese medicine. Compound 3 (Figure 5) was also detected in the leaves and stems of Leptocarpha rivularis DC., a member of the Asteraceae [19]. These hydroxybenzoic acid derivatives have not been detected in the Achillea species to the best of our knowledge before. Furthermore, an apigenin-6,8-di-C-hexoside (6) has not been described for $A$. atrata before and has previously been identified in the aerial parts of $A$. setacea W. et K. [18]. Mass spectral analysis of this compound revealed an $[\mathrm{M}-\mathrm{H}]^{-}$ion at $\mathrm{m} / \mathrm{z} 593$ and the release of two C-hexose moieties ([M-H-120-120] ${ }^{-}$), thus yielding characteristic fragment ions at $\mathrm{m} / \mathrm{z}$ 473 and $m / z$ 353, which is in accordance with the findings of Spínola and Castilho (2017) [9]. Similar to the aforementioned compound discoveries for A. atrata, a dimethoxyflavanone derivative (9) with an $[\mathrm{M}-\mathrm{H}]^{-}$ion at $m / z 567$ and fragment ions at $m / z 341$ and $m / z 314$ has not been published for $A$. atrata before. Methyl and methoxy derivatives of flavonoid aglycones are accumulated by most Achillea species and are among the most frequently detected phenolic compounds in the genus Achillea [20], so it is not surprising that methoxy derivatives have also been detected in A. atrata in the present work. A comparison with polymethoxyflavones already known for Achillea species, i.e., casticin, artemetin, salvigenin, and nepetin, did not reveal agreement of their spectrometric and chromatographic features in the current investigation. Due to the lack of literature data, a precise identification of compound 9 is therefore still pending. In addition, a dicaffeoylquinic acid-O-hexoside (12) was identified, which, to the best of our knowledge, has not yet been reported in any Achillea species before. Compound assignment was based on a base peak at $m / z$ 
677, showing an $\mathrm{O}$-hexose cleavage ([M-H-162 $\left.]^{-}\right)$upon CID releasing the corresponding fragment ion at $m / z 515$ and being also in accordance with the data of Spínola and Castilho (2017) [9]. In contrast to the aforementioned compounds, caffeoyl/feruloyl derivatives of quinic acid (24) have already been described in the leaves of A. millefolium, i.e., 1-caffeoyl-3feruloylquinic acid and 1-caffeoyl-4-feruloylquinic acid [21]. In our study, compound 24 showed a fragmentation behavior typical of this component class: it yielded an $[\mathrm{M}-\mathrm{H}]^{-}$ion at $m / z 529$ which produced fragment ions at $m / z 367$ [feruloylquinic acid- $\mathrm{H}]^{-}$and $m / z$ 191 [quinic acid-H] ${ }^{-}$in CID experiments.

3,3'-O-dimethyl-ellagic acid<smiles>COc1c(O)cc2c(=O)oc3c(OC)c(O)cc4c(=O)oc1c2c34</smiles>

\section{3,4'-O-dimethyl-ellagic acid}<smiles>COc1cc2c(=O)oc3c(OC)c(O)cc4c(=O)oc(c1O)c2c34</smiles>

Figure 4. Chemical structure of potential isomers of 1 (3,3'-O-dimethyl-ellagic acid and 3,4'-Odimethyl-ellagic acid).

\section{Syringic acid-4- $O$-glucoside Protocatechuic acid-4- $O$-glucoside}<smiles>COc1cc(C(=O)O)cc(OC)c1OC1OC(CO)C(O)C(O)C1O</smiles><smiles>O=C(O)c1ccc(OC2OC(CO)C(O)C(O)C2O)c(O)c1</smiles>

Figure 5. Chemical structures of potential isomers of 2 and 3 (syringic acid-4-O-glucoside and protocatechuic acid-4-O-glucoside).

\section{Discussion}

\subsection{Impact of Environmental Conditions on the Growth of A. atrata $L$.}

The cultivation of $A$. atrata and other alpine snowbed plants, such as Achillea clusiana L. and Gnaphalium hoppeanum W. D. J. Koch, was also studied by Dullinger and Huelber (2011) [22]. For this purpose, the aforementioned species were cultivated in the lower alpine zone of the northeastern Calcareous Alps of Austria (1850 to $1950 \mathrm{~m}$ a.s.l.) over a period of three years using a substrate composed of one part calcareous sand, one part compost and two parts mineral soil. Comparable to the findings of our study, the generative reproduction was very low for all alpine species despite applying suitable cultivation conditions. A. atrata and A. clusiana did not develop inflorescences in the first 
year of cultivation. Only in the following years generative plants were observed [22]. In our study, only two of the plants cultivated in Germany were in the generative phase and developed flowers. Compared to the aforementioned study, the soil applied in the present study was characterized by higher limestone gravel proportions and less compost. This probably had a positive effect on plant development, resulting in one plant in the generative phase already in the first vegetation period. However, the factors responsible for the poor rate of blooming still need to be clarified. In contrast, soil rich in compost was used for cultivation in Switzerland. Due to the high nutrient content of the soil, the plants developed numerous lateral shoots, however, without reaching the generative phase. Thus, it may be assumed that this soil composition is suboptimal for cultivation of $A$. atrata and does not correspond to its natural habitat. This Achillea species is adapted to nutritionally very poor alpine habitats, so compost strongly promotes vegetative development and is not ideal for inducing flower formation. Especially the major nutrients nitrogen/nitrate and phosphate are very important for flower formation [23]. Kant et al. (2011) [24] demonstrated nitrate and phosphate to have opposite effects on flowering in Arabidopsis thaliana L. Heynh. Higher phosphate and lower nitrate concentrations promoted flowering and affect the flowering time [23]. Further studies have been reported assessing the influence of main and trace elements on the development, survival and growth of seedlings, juvenile as well as adult plants of various Achillea species. In the case of A. millefolium optimal nutrient supply as based on nitrogen, phosphate and potassium levels allows cultivation even under adverse conditions, such as at high levels of heavy metals [25]. Nonetheless, it must be kept in mind that plant growth and development in general is dependent not only on soil composition but also climatic conditions, such as wind, temperature, precipitation, but also UV radiation and altitude. These factors are clearly interrelated and do not act individually nor with the same impact [26].

Based on our results, cultivation of $A$. atrata can be realized at sites differing significantly in altitude and, consequently, in their climatic conditions and soil composition. With a soil composition of $25 \%$ compost, $30 \%$ limestone gravel and further soil components, this alpine Achillea species might be successfully cultivated in Germany, yielding a phenotype similar to that of the wild type. Furthermore, our results confirmed that altitude among others is only one parameter decisive for successful cultivation. In a direct comparison of the two cultivation setups, the location in Germany at an altitude of $410 \mathrm{~m}$ a.s.l. appeared more suitable due to low mortality rates. In contrast to other studies reported in the literature, we succeeded in reaching the generative phase already in the first vegetation period of cultivation. Although the plants only reached a height of 7 to $10 \mathrm{~cm}$, they were still within the range of 5 to $25 \mathrm{~cm}$ described by other authors for the wild types [27]. To improve cultivation, biotic factors also need to be considered. According to the literature findings of Dullinger and Huelber (2011) [22], cultivation of A. atrata in a community of different alpine plants may result in increased survival rates. In Germany, a long-lasting snow cover, that protects the plants from climatic extremes and consequently enables successful hibernation, is not guaranteed. Consequently, the plants should be covered during winter months to reduce the need of reseeding in the subsequent vegetation period. In summary, field experiments are suitable for establishing particularly demanding plants under environmental conditions that do not correspond to their natural habitats. Since a fairly high number of abiotic and biotic environmental factors affect growth controlled conditions in a greenhouse would allow to reduce the complexity of parameters that need to be considered and may contribute to further optimize the cultivation of A. atrata.

\subsection{Impact of Environmental Conditions on the Phenolic Profile of Achillea atrata $L$.}

The results indicate that environmental conditions only have a minor influence on the qualitative composition of the secondary metabolite profile of the investigated $A$. atrata plants, whereas the quantity of individual phenolic compounds is particularly dependent on the altitude of the location. Rather, the genotype and the associated chemotype may play a decisive role for the metabolome of $A$. atrata. Although raised under different conditions, 
the profiles of cultivated plants in Germany and Switzerland were more similar than those of the latter with wild type plants grown in the alpine habitat. This suggests genetic reasons for the different profiles, although the existence of different chemotypes of $A$. atrata has not been reported in the previous literature. This is, among others, due to the fact that most studies refer to the best-known Achillea species, A. millefolium, which is known to include several chemotypes [20]. For instance, the data of Gudaityte et al. (2007) [28] clearly indicate a remarkable chemical polymorphism within the population of A. millefolium in Lithuania. According to the major essential oil components, six different chemotypes of A. millefolium could be distinguished. Similar results were also obtained for A. collina [29]. Thus, the existence of different chemotypes also of the alpine species A. atrata appears conclusive. The aforementioned investigations were merely based on the identification and quantification of essential oil components of Achillea species from different habitats. However, to the best of our knowledge, corresponding studies of correlations between phenolic profile variations and different chemotypes are currently unknown for Achillea species. Thus, further investigations are imperative to verify the existence of different chemotypes also for $A$. atrata.

Furthermore, our analyses add further evidence that altitude is one of the main factors triggering the biosynthesis of phenolic components, thus resulting in enhanced levels, especially of UV-absorbing hydroxycinnamates. In total, 12 of 28 identified compounds could be assigned to this substance class, with dicaffeoylquinic acids (19-23) being the most abundant phenolic acids. Based on the report of Benedek et al. (2006) [30], 3,4-, 3,5- and 4,5-di-O-caffeoylquinic acids may be among these compounds. These caffeic acid derivatives have already been proven for $A$. millefolium and are the main choleretic principles in these Achillea species [30]. Moreover, they are involved in a wide range of plant stress responses and contribute to the protection of plants against high intensities of light and UV-B radiation. However, their concentration is significantly dependent on environmental conditions [31]. Previous studies of Giorgi et al. (2010) [31] revealed A. collina plants grown at higher altitudes (Italy, Bormio, $1050 \mathrm{~m}$ a.s.l.) display increased concentrations of chlorogenic acid; 3,5- and 4,5-di-O-caffeoylquinic acids; as well as an increased antioxidant capacity compared to plants grown at lower altitudes (Italy, Dazio, $600 \mathrm{~m}$ a.s.l.). Our quantitative analyses corroborate the findings of Giorgi et al. (2010) [31] stating that caffeic acid derivatives are present in high concentrations in the flowers. This suggests that phenolic components exert specific roles in the various plant organs to protect the plant from oxidative damage caused by climatic stress factors associated with altitude conditions [31]. Moreover, this thesis is supported by the fact that further differences in the occurrence of the identified phenolic compounds were observed between the flowers and leaves. Apigenin-6,8-di-C-hexoside (6), dicaffeoylquinic acid-O-hexoside (12), apigenin-7-O-glucoside (18), luteolin (25), apigenin (26), and centaureidin (27) were identified exclusively in the flowers, whereas quercetin-3-O-rutinoside (11) and kaempferol$3-O-$-rutinoside (16) were only detected in the leaves. The specific occurrence of apigenin6,8-di-C-hexoside (6), and dicaffeoylquinic acid-O-hexoside (12) in A. atrata flowers could not be verified by literature data, since previous studies mainly aimed at the phytochemical characterization of total extracts of aerial plant parts, whereas particularities of different plant organs were not considered [32]. In contrast, apigenin-7-O-glucoside, luteolin, and apigenin were detected both in flowers and leaves of various Achillea species. However, these latter components were present in higher amounts in flowers [33]. Only the detection of centaureidin (27) may be confirmed by the data of Valant-Vetschera and Wollenweber (1996) [34] and Aljanĉić et al. (1999) [3] demonstrating the leaves of A. atrata to be devoid of centaureidin, whereas flower constituents were not analyzed [34]. In addition, Aljanĉić et al. (1999) [3] demonstrated the occurrence of centaureidin in the aerial parts of A. atrata. Taking together both published and the present data, it can be concluded that centaureidin is specific to A. atrata flowers. In addition to the identification and quantification of further plant components, antimicrobial assays should also be included, in order to demonstrate the influence of concentration differences of $A$. atrata extracts and preparations. Further, 
bioactivity testing with extracts recovered from individual plant organs may contribute to in-depth understanding of the active principles of $A$. atrat $a$ and as quality markers for pharmaceutical preparations obtained therefrom.

Supplementary Materials: The following is available online at https://www.mdpi.com/article/10 .3390/pr9050853/s1, Table S1: Plan of Achillea atrata L. cultivation in Germany in the years 2015 to 2019. Composition of cultivation soil I: $32 \%$ wood fiber, $64 \%$ compost, and $4 \%$ sand. Composition of soil variant 1: $20 \%$ sand, $25 \%$ volcanic granulate, $25 \%$ wood fiber, compost, and $30 \%$ limestone gravel. Composition of soil variant 2: $30 \%$ sand, 35\% volcanic granulate, $35 \%$ wood fiber; Table S2: Plan of Achillea atrata L. cultivation in Switzerland in the years 2016 to 2019. Composition of cultivation soil II: $2 / 3$ peat-free soil consisting of bark humus and mineral structural materials and $1 / 3$ sand. Soil composition for the field: $70 \%$ compost, $15 \%$ wood fibers, $5 \%$ clay, $5 \%$ lava granules and limestone.

Author Contributions: Study conception and design: L.S., D.R.K., P.L.; Data acquisition: L.S., B.E.; Data analysis and interpretation: L.S.; Drafting of manuscript: L.S. and D.R.K., Critical revision throughout the study: D.R.K., F.C.S. and O.S. All authors have read and agreed to the published version of the manuscript.

Funding: This research received no external funding.

Acknowledgments: The authors thank Verena Berchtold (University of Zurich) for providing seeds of A. atrata L. as well as Susan Wacker, Lina Sandrin, and Tabea Ehrensperger (Schweibenalp, Brienz) for cultivating A. atrata in Switzerland.

Conflicts of Interest: The authors declare no conflict of interest.

\section{References}

1. Hess, H.E.; Landolt, E.; Hirzel, R. Flora der Schweiz und Angrenzender Gebiete: Plumbaginaceae Bis Compositae; Birkhäuser Basel: Basel, Switzerland, 1972; Volume 3, pp. 562-563.

2. Ristić, M.; Soković, M.; Grubišić, D.; Kovacević, N. Chemical Analysis and Antifungal Activity of the Essential Oil of Achillea atrata L. J. Essent. Oil Res. 2004, 16, 75-78. [CrossRef]

3. Aljanĉić, I.; Vajs, V.; Menković, N.; Karadźić, I.; Juranić, N.; Milosavljević, S.; Macura, S. Flavones and sesquiterpene lactones from Achillea atrata subsp. multifida: Antimicrobial activity. J. Nat. Prod. 1999, 62, 909-911. [CrossRef]

4. Apel, L.; Lorenz, P.; Urban, S.; Sauer, S.; Spring, O.; Stintzing, F.C.; Kammerer, D.R. Phytochemical characterization of different yarrow species (Achillea sp.) and investigations into their antimicrobial activity. Z. Naturforsch. C 2020, 76, 55-65. [CrossRef]

5. Salomon, L.; Lorenz, P.; Bunse, M.; Spring, O.; Stintzing, F.C.; Kammerer, D.R. Comparison of the Phenolic Compound Profile and Antioxidant Potential of Achillea atrata L. and Achillea millefolium L. Molecules 2021, 26, 1530. [CrossRef]

6. Carlen, C. Breeding and cultivation of medicinal plants. In Herbal Medicines: Development and Validation of Plant-Derived Medicines for Human Health; CRC Press: Boca Raton, FL, USA; Taylor \& Francis: Abingdon, UK, 2012; pp. 79-91.

7. Apel, L.; Kammerer, D.R.; Stintzing, F.C.; Spring, O. Comparative Metabolite Profiling of Triterpenoid Saponins and Flavonoids in Flower Color Mutations of Primula veris L. Int. J. Mol. Sci. 2017, 18, 153. [CrossRef] [PubMed]

8. Schuetz, M. Genetisch-ökologische Untersuchungen an alpinen Pflanzenarten auf verschiedenen Gesteinsunterlagen: Keimungsund Aussaatversuche. Ph.D. Thesis, ETH Zurich, Zürich, Switzerland, 1988.

9. Spínola, V.; Castilho, P.C. Evaluation of Asteraceae herbal extracts in the management of diabetes and obesity. Contribution of caffeoylquinic acids on the inhibition of digestive enzymes activity and formation of advanced glycation end-products (in vitro). Phytochemistry 2017, 143, 29-35. [CrossRef] [PubMed]

10. Barros, L.; Pereira, E.; Calhelhaa, R.C.; Dueñasc, M.; Carvalhoa, A.; Santos-Buelga, C.; Ferreira, I.C.F.R. Bioactivity and chemical characterization in hydrophilic and lipophilic compounds of Chenopodium ambrosioides L. J. Funct. Foods 2013, 5, 1732-1740. [CrossRef]

11. Raffaelli, A.; Moneti, G.; Mercati, V.; Toja, E. Mass spectrometric characterization of flavonoids in extracts from Passiflora incarnata. J. Chromatogr. A 1997, 777, 223-231. [CrossRef]

12. Han, J.; Ye, M.; Qiao, X.; Xu, M.; Wang, B.-R.; Guo, D.-A. Characterization of phenolic compounds in the Chinese herbal drug Artemisia annua by liquid chromatography coupled to electrospray ionization mass spectrometry. J. Pharm. Biomed. Anal. 2008, 47, 516-525. [CrossRef]

13. Manhita, A.; Balcaen, L.; Vanhaecke, F.; Ferreira, T.; Candeias, A.; Dias, C.B. Unveiling the colour palette of Arraiolos carpets: Material study of carpets from the 17th to 19th century period by HPLC-DAD-MS and ICP-MS. J. Cult. Herit. 2014, 15, $292-299$. [CrossRef]

14. De Rosso, M.; Panighel, A.; Vedova, A.D.; Gardiman, M.; Flamini, R. Characterization of Non-Anthocyanic Flavonoids in Some Hybrid Red Grape Extracts Potentially Interesting for Industrial Uses. Molecules 2015, 20, 18095-18106. [CrossRef] 
15. Gouveia, S.C.; Castilho, P. Characterization of phenolic compounds in Helichrysum melaleucum by high-performance liquid chromatography with on-line ultraviolet and mass spectrometry detection. Rapid Commun. Mass Spectrom. 2010, 24, 1851-1868. [CrossRef] [PubMed]

16. Parejo, I.; Jauregui, O.; Viladomat, F.; Bastida, J.; Codina, C. Characterization of acylated flavonoid-O-glycosides and methoxylated flavonoids from Tagetes maxima by liquid chromatography coupled to electrospray ionization tandem mass spectrometry. Rapid Commun. Mass Spectrom. 2004, 18, 2801-2810. [CrossRef] [PubMed]

17. Ola, S.S.; Catia, G.; Marzia, I.; Francesco, V.F.; Afolabi, A.A.; Nadia, M. HPLC/DAD/MS characterisation and analysis of flavonoids and cynnamoil derivatives in four Nigerian green-leafy vegetables. Food Chem. 2009, 115, 1568-1574. [CrossRef]

18. Khallouki, F.; Haubner, R.; Hull, W.; Erben, G.; Spiegelhalder, B.; Bartsch, H.; Owen, R. Isolation, purification and identification of ellagic acid derivatives, catechins, and procyanidins from the root bark of Anisophyllea dichostyla R. Br. Food Chem. Toxicol. 2007, 45, 472-485. [CrossRef] [PubMed]

19. Jiménez-González, A.; Quispe, C.; Bórquez, J.; Sepúlveda, B.; Riveros, F.; Areche, C.; Nagles, E.; García-Beltrán, O.; Simirgiotis, M.J. UHPLC-ESI-ORBITRAP-MS analysis of the native Mapuche medicinal plant palo negro (Leptocarpha rivularis DC-Asteraceae) and evaluation of its antioxidant and cholinesterase inhibitory properties. J. Enzym. Inhib. Med. Chem. 2018, 33, 936-944. [CrossRef]

20. Nemeth, E.; Bernath, J. Biological activities of yarrow species (Achillea spp.). Curr. Pharm. Des. 2008, 14, 3151-3167. [CrossRef]

21. Jaiswal, R.; Kiprotich, J.; Kuhnert, N. Determination of the hydroxycinnamate profile of 12 members of the Asteraceae family. Phytochemistry 2011, 72, 781-790. [CrossRef]

22. Dullinger, S.; Huelber, K. Experimental evaluation of seed limitation in alpine snowbed plants. PLoS ONE 2011, 6, e21537. [CrossRef]

23. Lin, Y.-L.; Tsay, Y.-F. Influence of differing nitrate and nitrogen availability on flowering control in Arabidopsis. J. Exp. Bot. 2017, 68, 2603-2609. [CrossRef]

24. Kant, S.; Peng, M.; Rothstein, S.J. Genetic Regulation by NLA and MicroRNA827 for Maintaining Nitrate-Dependent Phosphate Homeostasis in Arabidopsis. PLoS Genet. 2011, 7, e1002021. [CrossRef]

25. O'Dell, R.E.; Claassen, V.P. Serpentine and Nonserpentine Achillea millefolium Accessions Differ in Serpentine Substrate Tolerance and Response to Organic and Inorganic Amendments. Plant Soil 2006, 279, 253-269. [CrossRef]

26. Pott, R.; Hueppe, J. Spezielle Geobotanik: Pflanze-Klima-Boden; Springer: Berlin/Heidelberg, Germany, 2008 ; pp. $195-232$.

27. Godet, J.D. Alpenpflanzen: Nach Farben Bestimmen; Eugen Ulmer KG: Stuttgart, Germany, 2006; pp. 188-189.

28. Gudaityte, O.; Venskutonis, P.R. Chemotypes of Achillea millefolium transferred from 14 different locations in Lithuania to the controlled environment. Biochem. Syst. Ecol. 2007, 35, 582-592. [CrossRef]

29. Todorova, M.; Trendafilova, A.; Mikhova, B.; Vitkova, A.; Duddeck, H. Chemotypes in Achillea collina based on sesquiterpene lactone profile. Phytochemistry 2007, 68, 1722-1730. [CrossRef] [PubMed]

30. Benedek, B.; Geisz, N.; Jager, W.; Thalhammer, T.; Kopp, B. Choleretic effects of yarrow (Achillea millefolium s.l.) in the isolated perfused rat liver. Phytomedicine 2006, 13, 702-706. [CrossRef] [PubMed]

31. Giorgi, A.; Madeo, M.; Speranza, G.; Cocucci, M. Influence of environmental factors on composition of phenolic antioxidants of Achillea collina Becker ex Rchb. Nat. Prod. Res. 2010, 24, 1546-1559. [CrossRef] [PubMed]

32. Marchart, E.; Kopp, B. Capillary electrophoretic separation and quantification of flavone-O- and C-glycosides in Achillea setacea W. et K. J. Chromatogr. B 2003, 792, 363-368. [CrossRef]

33. Karl'ová, K. Accumulation of flavonoid compounds in flowering shoots of Achillea collina Becker ex. Rchb. Alba during flower development. Hortic. Sci. 2011, 33, 158-162. [CrossRef]

34. Valant-Vetschera, K.M.; Wollenweber, E. Leaf exudate flavonoids of Achillea clusiana Tausch and related species. Biochem. Syst. Ecol. 1996, 24, 477-478. [CrossRef] 